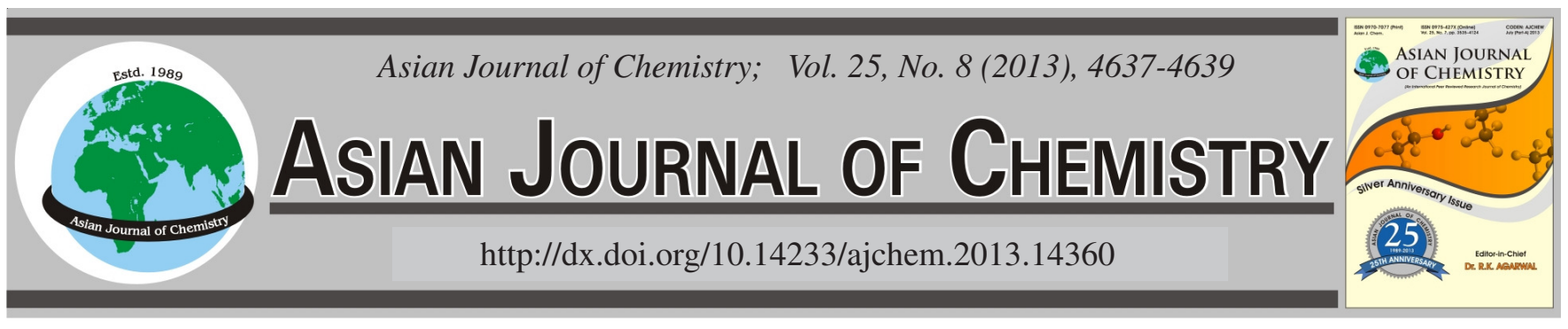

\title{
Synthesis of Water Soluble Chitosan-Artemisinin Conjugate
}

Dan XiaO, Bo Yang ${ }^{*}$, Xue-Min Yang, Dong Yi, Xia-Li Liao, Jian Yang and Chuan-Zhu GaO

Faculty of Life Science and Technology, Kunming University of Science and Technology, Kunming 650500, P.R. China

*Corresponding author: Tel: +86 13064281879; E-mail: yangbo6910@sina.com; xiaodan19871124@yahoo.com.cn

(Received: 24 July 2012;

Accepted: 18 February 2013)

AJC-13030

The conjugate was prepared through a series of reactions, starting from the hydrogenation of artemisinin and then acylation, hydrolysis and condensation. The solubility of chitosan-artemisinin conjugate was evaluated and compared with a normal commercially available artemisinin. The results indicated that the conjugate had much higher solubility in comparison with artemisinin. The method reported in this paper provides a good yield of chitosan-artemisinin conjugate, chitosan-artemisinin could be attributed to increasing the bioavailability in artemisinin delivery.

Key Words: Artemisinin, Chitosan, Conjugate, Water soluble.

\section{INTRODUCTION}

Malaria represents one of the most dangerous diseases in many tropical and subtropical areas, as more than 500 million people result infected annually and as one person (mostly children) is estimated to die in every $12 \mathrm{~s}$ due to the consequences of this infection ${ }^{1}$. Artemisinin (Fig. 1) is the active principle of the Chinese traditional antimalarial drug Artemisia annua $\mathrm{L}^{2}$. It has semisynthetic derivatives, such as dihydroartemisinin and artemether, are effective against both chloroquine-sensitive and chloroquine-resistant $P$. falciparum and are clinically used for the treatment of cerebral malaria ${ }^{3}$. In recent years, Artemisinin has been shown to be effective in killing cancer cells ${ }^{4-6}$. However, Artemisinin is a poorly water soluble drug and has low bioavailability by oral administration due to slow drug dissolution and decomposition in stomach and intestine?

Chitosan (Fig. 2) which is a natural cationic polysaccharide composed by $\beta$-(1-4)-linked glucosamine units together with some $\mathrm{N}$-acetyl-d-glucosamine units, is obtained by exhaustive deacetylation of chitin ${ }^{8}$. Owing to the favourable biodegradable, nontoxic and antimicrobial properties, chitosan has been used in different biomedical and drug delivery applications $^{9,10}$.

Chen and $\operatorname{Lin}^{11}$ have reported of artemisinin nanocapsules as anticancer drug delivery systems. Usuda et al. ${ }^{12}$ use several kinds of cyclodextrins as solubilizers was examined, our previous work indicated that hydroxypropyl-cyclodextrin complexed with artemether and the complex produces a 1.81fold enhancement in apparent bioavailability compared to artemether ${ }^{13}$. In this paper, we have focused on the solubilization and stabilization effect of conjugate, after hydrogenation, substitution and condensation. Results show that have much higher solubility compared to artemisinin. The method reported in this paper provides a good yield of the chitosan-artemisinin conjugate and it could be attributed to increasing the bioavailability in artemisinin delivery.

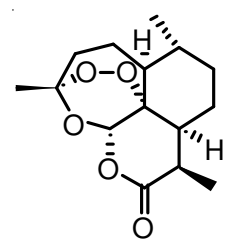

Fig. 1. Structure of the artemisinin

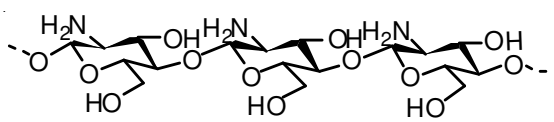

Fig. 2. Structure of the chitosan

\section{EXPERIMENTAL}

Artemisinin was obtained from Kunming Pharmaceutical Corporation (PC > $99 \%$ ) in Yunnan Province, P. R. China. Chitosan was commercially available $(\overline{\mathrm{M}} \mathrm{n}=1800, \overline{\mathrm{M}} \mathrm{w} / \overline{\mathrm{M}} \mathrm{n}$ =1.31) (Nanjing Reagent Factory). N,N-Dimethyl formamide (DMF) was predried over calcium hydride for 2 days and then distilled under a reduced pressure prior to use. 4-Dimethylamiopryidine (DMAP) was commercially available (Chengdu Reagent Factory). Dicyclohexylcarbodiimide (DCC) was 
commercially available (Shanghai Reagent Factory) and used without further purification. Other chemicals and solvents were of analytical-reagent grade and deionized double-distilled water was used throughout the study.

All reactions were monitored by TLC, melting points were determined by the capillary method without correction. ${ }^{1} \mathrm{H}$ NMR spectra and MS data were recorded on a Bruker DRX 500 NMR spectrometer and a ZAB-2F mass spectrometer, respectively.

Synthesis of dihydroartemisinin (2): To a stirred solution of artemisinin $1.500 \mathrm{~g}$ ( $5 \mathrm{mmol})$ in $\mathrm{MeOH}(130 \mathrm{~mL})$ and maintained at $0-5{ }^{\circ} \mathrm{C}$, the mixture was added $\mathrm{NaBH}_{4} 1.300 \mathrm{~g}(24$ mol), it was stirred at $0-5^{\circ} \mathrm{C}$ for $1 \mathrm{~h}$. Acetic acid was added to adjust the $\mathrm{pH}=7$, then it was added to cold water $(100 \mathrm{~mL})$ and stirred for $15 \mathrm{~min}$ at room temperature. The white precipitate was collected and washed with $\mathrm{H}_{2} \mathrm{O}-\mathrm{MeOH}(2: 1,2 \mathrm{~mL}$ $\times 200 \mathrm{~mL}$ ). The wet crops were pooled and dissolved in $\mathrm{CH}_{2} \mathrm{Cl}_{2}$ $(4 \mathrm{~mL} \times 30 \mathrm{~mL})$. After drying $\left(40 \mathrm{~g} \mathrm{MgSO}_{4}\right)$ and evaporation of the solvent, the solution are dried over anhydrous sodium sulfate and solvent was removed in vacuo to afford white solid $\left(1.260\right.$ g) $84 \%$ yield. m.p. $147-150\left(\right.$ lit $\left.^{14} 149-153{ }^{\circ} \mathrm{C}\right) .{ }^{1} \mathrm{H}$ NMR $\left(500 \mathrm{MHz}, \mathrm{CDCl}_{3}\right): 5.61-5.39(\mathrm{~m}, 1 \mathrm{H}, \mathrm{O}-\mathrm{CH}-\mathrm{O}), 5.30-4.76$ (d, 1H, CHOH), $2.63\left(\mathrm{~m}, 0.5 \mathrm{H}, \mathrm{CHCH}_{3}\right), 0.91-1.02(\mathrm{~m}, 6 \mathrm{H}$, $\left.\mathrm{CHCH}_{3}\right), \mathrm{MS}(\mathrm{m} / \mathrm{z}): 284\left(\mathrm{M}^{+}\right)$.

Synthesis of artesunate (3): To a solution of succinic anhydride $(1.260 \mathrm{~g}, 12.6 \mathrm{mmol})$ in dry acetone $(10 \mathrm{~mL})$, triethylamine (1.23 mmol), dihydroartemisinin (2) (500 mg, 1.8 mmol) was added dropwise at room temperature over a period of $9 \mathrm{~h}$ under an $\mathrm{N}_{2}$ atmosphere. The resulting solution was poured into water $(80 \mathrm{~mL})$ and then neutralized to $\mathrm{pH} 3-4$ with $1 \mathrm{M} \mathrm{HCl}$, the mixture was cooled to $0{ }^{\circ} \mathrm{C}$, the wet crops were pooled and dissolved in $\mathrm{CH}_{2} \mathrm{Cl}_{2}(4 \mathrm{~L} \times 30 \mathrm{~L})$. And then the precipitate was filtrated, dried in vacuo to obtain 3 (275 mg) white solid in $38 \%$ yield; m.p. $142-146^{\circ} \mathrm{C}\left(\right.$ lit $^{15} .139-143$ $\left.{ }^{\circ} \mathrm{C}\right) .{ }^{1} \mathrm{H}$ NMR $\left(500 \mathrm{MHz}, \mathrm{CDCl}_{3}\right): 5.80(\mathrm{~d}, 1 \mathrm{H}, \mathrm{O}-\mathrm{CH}-\mathrm{OC}=\mathrm{O})$, 5.44 (s 1H O-CH-O) 2.64-2.78 (m, $4 \mathrm{H}, \mathrm{O}=\mathrm{CCH}_{2}$ ), 2.55-2.60 (m, IH, $\mathrm{CHCH}_{3}$ ) , 2.34-2.42 (m, IH), 0.99-1.03 (m, IH), 0.97 (d, $\left.3 \mathrm{H}, \mathrm{CHCH}_{3}\right), 0.85$ (d, 3H, $\left.\mathrm{CHCH}_{3}\right) . \mathrm{MS}(\mathrm{m} / \mathrm{z}): 384\left(\mathrm{M}^{+}\right)$.

Synthesis of chitosan-artemisinin conjugate (4): To solution of artesunate (3) $384 \mathrm{mg}$ (1.0 mmol) in dry DMF (50 $\mathrm{mL})$, Chitosan $180 \mathrm{mg}(0.1 \mathrm{mmol})$ and dicyclohexylcarbodiimide (DCC) $226 \mathrm{mg}$ (1.1 mmol) was added. The reaction mixture was stirred for 2 days in an ice bath and another 2 days at room temperature and then allowed to stand for $1 \mathrm{~h}$. The precipitate was removed by filtration and the filtrate was poured into $300 \mathrm{~mL}$ of acetone. The precipitate was collected and subsequently purified on a Sephadex G-25 column with water as eluent. after the residue was dried in vacuo, we got the yellow solid (408 mg) in $75 \%$ yield. ${ }^{1} \mathrm{H}$ NMR $(500 \mathrm{MHz}$, $\mathrm{D}_{2} \mathrm{O}+\mathrm{HCl}$ ): 5.80-5.44 (m, O-CH-O), 2.64-2.78 (m, O=CCH $\mathrm{CCH}_{2}$, 3.649-3.874 (m, H-3, H-4, H-5, H-6 of chitosan), 3.280-3.312 ( $\mathrm{H}-2$ of chitosan), 0.97 (d, $\left.\mathrm{CHCH}_{3}\right), 0.87$ (m, $\left.\mathrm{CHCH}_{3}\right)$.

Measurement of water solubility: The water solubility of chitosan-artemisinin conjugate was assessed by preparation of its saturated aqueous solution ${ }^{16}$. An excess amount of complex was put in $5 \mathrm{~mL}$ of water $(\mathrm{pH} \mathrm{ca.7)}$ ) and the mixture was stirred for $1 \mathrm{~h}$. After removing the insoluble substance by filtration, the filtrate is evaporated under reduced pressure to dryness and the residue is dosed by weighing method.

\section{RESULTS AND DISCUSSION}

Two kinds of chitosan-artemisinin conjugate that contain different amounts of artemisinin were synthesized according to the synthetic route shown in Fig. 3. The results are summarized in Table-1. The chitosan-artemisinin conjugate in the polymers prepared in this experiment was 0.60 and 0.75 mol- $\%$, respectively and could be controlled by varying the feed ratio between chitosan and artesunate (3). All the polymers obtained showed high water solubility. The chemical composition of the polymers was confirmed by means of ${ }^{1} \mathrm{H}$ NMR. Fig. 4 shows a representative ${ }^{1} \mathrm{H}$ NMR spectrum of the chitosan-artemisinin conjugate, demonstrating the presence of covalently bound chitosan amide in the polymers. We can calculate the produced rate, according to ${ }^{1} \mathrm{H}$ NMR spectrum Table-2 show that the solubility of artemisinin is $0.084 \mathrm{~g} / \mathrm{dL}$, the chitosan-artemisinin conjugate (4) was $3.123 \mathrm{~g} / \mathrm{dL}$. It is better than previously reported data ${ }^{15}$.

TABLE-1

SYNTHETIC RESULTS DERIVED FROM CHITOSAN-ARTEMISININ CONJUGATE

\begin{tabular}{cccc}
$\begin{array}{c}\text { Molar feed ratio } \\
\text { chitosan/artesunate (3) }\end{array}$ & $\begin{array}{c}\overline{\mathrm{Mn}} \\
(\mathrm{g} / \mathrm{mol})^{\mathrm{a}}\end{array}$ & $\begin{array}{c}\overline{\mathrm{M}} \\
(\mathrm{g} / \mathrm{mol})^{\mathrm{b}}\end{array}$ & $\begin{array}{c}\text { Yield } \\
(\mathrm{mol} \%)\end{array}$ \\
\hline $1: 8$ & 4728 & 2931 & 62 \\
$1: 10$ & 5460 & 4095 & 75 \\
\hline
\end{tabular}

${ }^{a}$ Theoretical value. ${ }^{b}$ Calculated from the peak integration of ${ }^{1} \mathrm{H}$ NMR spectra.

TABLE-2

PHYSICOCHEMICAL PROPERTIES OF ARTEMISININ AND CHITOSAN-ARTEMISININ CONJUGATE

\begin{tabular}{lcc}
\hline \multicolumn{1}{c}{ Compound } & m.p. $\left({ }^{\circ} \mathrm{C}\right)$ & Solubility $(\mathrm{g} / \mathrm{dL})^{\mathrm{a}}$ \\
\hline Artemisinin & 156 & 0.084 \\
Chitosan-artemisinin conjugate & - & 3.123 \\
\hline${ }^{a}$ In water at $25^{\circ} \mathrm{C}$. & &
\end{tabular}

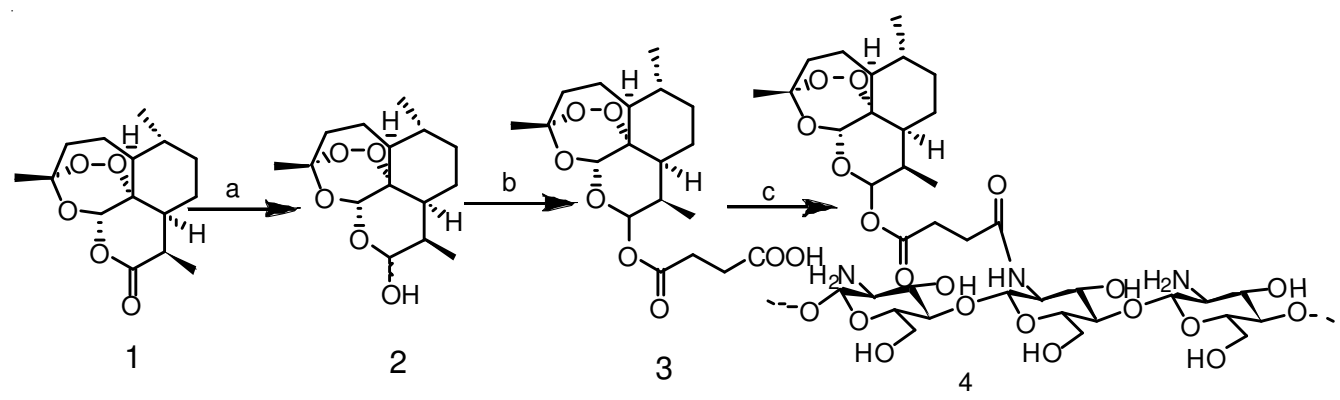

Reagents and conditions: (a) $\mathrm{NaBH}_{4}$ (b)an hydride (c)DCC

Fig. 3. Synthesis of chitosan/artemisinin derivatives 


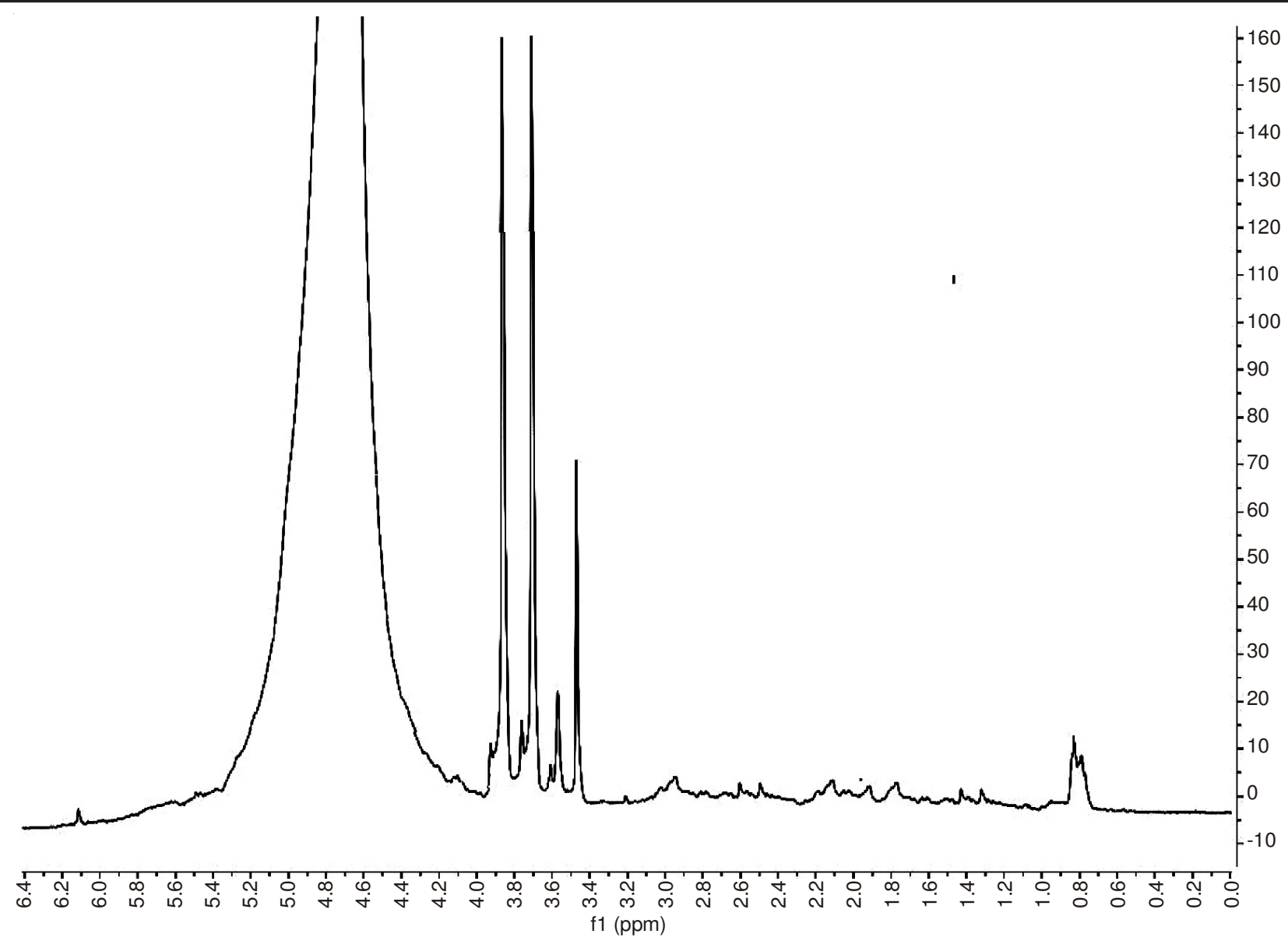

Fig. 4. ${ }^{1} \mathrm{H}$ NMR spectrum of chitosan-artemisinin conjugate (4) in $\mathrm{D}_{2} \mathrm{O}$

\section{Conclusion}

We successfully prepared conjugate after hydrogenation, substitution and condensation. Results show that have much higher solubility compared to artemisinin. This could be attributed to increasing the bioavailability in artemisinin delivery.

\section{ACKNOWLEDGEMENTS}

This work was supported by National Natural Science Foundation of China (NNSFC) (No. 21062009), Science Foundation of Kunming University of Science and Technology, and the Natural Science Foundation of Yunnan Province (No. 2009ZC045M), Meanwhile, all authors expressed their deep thanks to the Analysis and Testing Foundation of Kunming University of Science and Technology.

\section{REFERENCES}

1. G. Marshall, Science, 290, 428 (2000).

2. D.L. Klayman, Science, 228, 1049 (1985).

3. X.D. Luo and C.C. Shen, Med. Res. Rev., 7, 29 (1987).
4. H. Lai and N.P. Singh, Cancer Lett., 91, 41 (1995).

5. T. Efferth, H. Dunstan and A. Sauerbrey, H. Miyachi and C.R. Chitambar, Int. J. Oncol., 18, 767 (2001).

6. T. Efferth, A. Benakis, M.R. Romero, M. Tomicic, R. Rauh, D. Steinbach, R. Häfer, T. Stamminger, F. Oesch, B. Kaina and M. Marschall, Free Radic. Biol. Med., 37, 998 (2004).

7. I. Nakase, H. Lai, N.P. Singh and T. Sasaki, Int. J. Pharm., 28, 354 (2008).

8. N. Bhattarai, J. Gunn and M.Q. Zhang, Adv. Drug. Deliv. Rev., 62, 83 (2010).

9. Y.B. Schuetz, R. Gurny and O. Jordan, Eur. J. Pharm. Biopharm., 68, 19 (2008).

10. J. Wu and M. Sailor, Adv. Funct. Mater., 19, 73 (2009).

11. Y.F. Chen and X.F. Lin, Exp. Nano. Pharm. Res., 5, 316 (2009).

12. M. Usuda, T. Endo, H. Nagase and K. Tomono and H. Ueda, Drug Dev. Ind. Pharm., 26, 613 (2000).

13. B. Yang, J. Lin, Y. Chen and Y. Liu, Bioorg. Med. Chem., 17, 6311 (2009).

14. A. Brossi, B. Venugopalan, G.L. Dominguez, H.J. Yeh, J.L. FlippenAnderson, P. Buchs, X.D. Luo, W. Milhous and W. Peters, J. Med. Chem., 31, 645 (1988).

15. R.K. Haynes, H.-W. Chan, M.-K. Cheung, W.-L. Lam, M.-K. Soo, H.-W. Tsang, A. Voerste and I.D. Williams, Eur. J. Org. Chem., 113 (2002).

16. R.C. Petter, J.S. Salek, C.T. Sikorski, R.C. Petter, J.S. Salek, C.T. Sikorski, G. Kumaravel and F.T. Lin, J. Am. Chem. Soc., 112, 3860 (1990). 